\title{
SISTEMA INTEGRADO DE GESTÃO DE POLOS EAD - SIGESPOUMA EXPERIÊNCIA COLABORATIVA EM PARCERIA COM SEUS MANTENEDORES
}

\author{
ITUPEVA/SP MAIO/2018
}

\author{
MARIA CRISTINA MENDONÇA SIQUEIRA - CRUZEIRO DO SUL - cristinamendonca.sp@gmail.com \\ Bruna Carvalho Carita - UNIFRAN - brunabauhaus@gmail.com \\ Adriana Aparecida Furlan - CRUZEIRO DO SUL - afurlan3@gmail.com \\ Carlos Fernando Araújo Jr - CRUZEIRO DO SUL - cfaraujo@gmail.com \\ Katia Maria Rocha de Lima - CRUZEIRO DO SUL - katia.lima81@gmail.com
}

Tipo: Relato de Experiência Inovadora (EI)

Categoria: Estratégias e Políticas

Setor Educacional: EDUCAÇÃO SUPERIOR

\begin{abstract}
RESUMO
Esse trabalho relata a experiência inovadora de um Grupo Educacional Brasileiro, que possui atualmente 04 instituições credenciadas e uma rede de 430 polos parceiros distribuídos por todas as regiões do Brasil,para oferta de cursos superiores na modalidade EaD,por meio da criação de uma comissão de mantenedores desses polos credenciados e gestores internos da instituição em estudo. $O$ objetivo dessa iniciativa foi ampliar a participação desses atores na gestão do processo EAD, a fim de alcançar um aprimoramento no atendimento e relacionamento com seus alunos contribuindo assim para um aprendizado eficaz e diferenciado dos mesmos. O crescimento expressivo do número de polos por todo território nacional pode ser verificado a partir da publicação pelo Ministério de Educação e Cultura -MEC, da Portaria Normativa no 11 de 20/06/2017, que, entre outras novas diretrizes, flexibiliza a criação de polos ead diretamente pela Instituição de Ensino Superior, credenciada para a oferta de cursos na modalidade EAD. Este fato gerou a necessidade das IES passarem a ter um novo olhar para o modelo de Gestão de Polos de forma a estarem mais atentos a supervisão do funcionamento e atendimento prestado por essas unidades, consideradas como um prolongamento das instituições de ensino que representam, de modo a garantir a observância da legislação vigente e o cumprimento das diretrizes educacionais previstas nos PDIs e PPCs das IES. Foram convidados inicialmente um grupo de 10 mantenedores de polos parceiros para discussão e proposição de ações que viessem a colaborar para o atendimento do objetivo proposto que, acima de tudo,busca proporcionar uma formação acadêmica de qualidade para os discentes. A pronta adesão e a disposição colaborativa dos participantes,gerou em seu primeiro ano de trabalho, resultados importantes a partir da análise de potencialidades e fragilidades do processo EAD do grupo educacional e apontou oportunidades de ajustes e melhorias em diversos processos dos cursos EaD.
\end{abstract}

Palavras-chave: GESTÃO INTEGRADA DE POLOS EAD, GESTÃO DE POLOS EAD, POLOS EAD, EDUCAÇÃO A DISTÂNCIA

\section{AGRADECIMENTOS}

OS AUTORES AGRADECEM A TODOS MANTENEDORES DE POLOS EAD ECOLABORADORES DA CRUZEIRO DO SUL EDUCACIONAL QUE PARTICIPARAM E CONTRIBUÍRAM COM SUAS CRÍTICAS E SUGESTÕES PARA O DESENVOLVIMENTO DESSE TRABALHO 


\section{INTRODUÇÃO}

A educação no Brasil tem sido pauta de discussões de diversas instâncias dos setores públicos, privado e, também, da sociedade civil que há décadas busca dar um rumo em relação ao crescimento da oferta de cursos em todos os níveis de ensino, bem como facilitar o acesso da população a este.

Embora, conforme Barros (2017), a educação a distância (EaD) não seja um instrumento recente a serviço do ensino, pois seus experimentos iniciais remontam ao início século XIX, ganhando impulso no fim do mesmo século XX, com o incremento das tecnologias de informação e comunicação e expansão da internet pelo país, esta modalidade de ensino tem se tornado uma realidade com amplo alcance e de forma concreta.

No âmbito da educação superior, as metas dos governos que se pautam na ampliação da oferta de acesso da população à formação profissional em nível universitário, tem se mantido aquém do esperado para que se tenha esse acesso.

Os responsáveis por políticas em nível institucional e governamental têm introduzido a educação a distância para atender àquilo que consideram certas necessidades, o que inclui: acesso crescente a oportunidades de aprendizado e treinamento; proporcionar oportunidades para atualizar aptidões; melhorar a redução de custos dos recursos educacionais; apoiar a qualidade das estruturas educacionais existentes; melhorar a capacitação do sistema educacional; nivelar desigualdades entre grupos etários; direcionar campanhas educacionais para públicos-alvo específicos; proporcionar treinamento de emergência para grupos-alvo importantes; aumentar as aptidões para a educação em novas áreas de conhecimento; oferecer uma combinação de educação com trabalho e vida familiar; agregar uma dimensão internacional à experiência educacional. ( MOORE e KEARSLEY,2008).

A educação a distância - EaD, tem crescido de forma exponencial em todo o mundo. No Brasil, havia, em 2004, cerca de 60.000 alunos matriculados em cursos de graduação e em 2016, alcançou a marca de 1,5 milhão de matriculas, segundo levantamento realizado pelo Censo da Educação Superior (2016), oferecendo assim importante contribuição para a expansão da oferta da educação superior no país.

Paralelamente, observa-se um aumento de quase $90 \%$ no número de polos de ensino a distância, nos seis primeiros meses de vigência das novas regras do governo para abertura dessas unidades, a partir da publicação, em junho de 2017, da Portaria 
Normativa no 11 de 20 de junho de 2017, que, entre outras novas diretrizes, flexibiliza a criação de polos ead diretamente pela Instituição de Ensino Superior credenciada para a oferta de cursos na modalidade EAD, por ato próprio e cadastro no Sistema e-Mec. $\mathrm{Na}$ época, havia 7,1 mil polos cadastrados. Em dezembro último, esse número alcançou a marca de 13,2 mil unidades credenciadas.

Com o intuito de adentrar na Era Digital, o Grupo Educacional descrito nesse trabalho, que atua no neste segmento há 50 anos, inicia em 2001 seus estudos sobre EaD, por meio de um grupo de pesquisa na Pós-Graduação Stricto Sensu. Em 2006 começa operacionalizar suas atividades no ensino a distância, a partir a utilização do Blackboard, O Ambiente Virtual de Aprendizagem-AVA escolhido, com a oferta de $20 \%$ a distância da carga horária das disciplinas dos cursos de graduação presenciais.

Esta experiência, que envolve a gestão da plataforma AVA, produção de material didático, capacitação dos professores e tutores e gestão da modalidade a distância permitiu o acumulo de know how no trato com a educação a distância. Como consequência e por conta de, na década de a partir de 2010, iniciar a incorporação de novas instituições de ensino superior, o Grupo mostrou-se suficientemente fortalecido para aprofundar e dar início a suas atividades no universo da educação a distância de forma mais ampla.

Nesse sentido, além do aperfeiçoamento dos setores envolvidos tornou-se necessário estabelecer uma relação direta e efetiva com os Polos parceiros, através de um programa de gestão e acompanhamento acadêmico e administrativo dos mesmos.

Especialmente, partir da publicação da Portaria Normativa nำ 11, DE 20 DE JUNHO DE 2017, que estabelece normas para o credenciamento de instituições e a oferta de cursos superiores a distância (a partir do Decreto no 9.057, de 25 de maio de 2017), tornou-se necessário estabelecer uma sistemática de acompanhamento das atividades e aprofundamento do acompanhamento dos Polos parceiros.

Em função dessa necessidade, com a expansão do número de Polos parceiros das três instituições de ensino superior que compõem o Grupo Educacional, criou-se um grupo de trabalho denominado, Comissão Permanente de Mantenedores de Polos EAD, articulada com a Coordenação Geral de Polos e Coordenação dos Cursos de Graduação, com o intuito de, através de reuniões regulares, discutir questões relativas a busca de melhoria na relação Polo e Universidade com a finalidade de promover um atendimento de excelência ao aluno e fortalecer as bases de conhecimento e qualidade para sua formação profissional. 
Esta Comissão foi formada inicialmente com representantes das áreas internas que atuam na gestão do EAD e mais mantenedores de dez Polos Parceiros, indicados para um ano de participação na comissão. Cada polo representou uma quantidade de outros Polos. O Polo representante passou a ser um intermediário entre a Instituição e os seus representados. A cada reunião outros colaboradores do Grupo Educacional eram convidados a participar em função dos temas elencados para discussão e estudo.

Em seu primeiro ano de funcionamento a Comissão avançou no relacionamento da Instituição com os Polos parceiros e na solução de problemas, bem como na implantação de novas ações que visavam melhorar o atendimento ao aluno e ao Polo.

\section{A Criação da Comissão Permanente de Mantenedores de Polos EAD}

A motivação da gestão integrada dos Polos EAD, por meio da criação de uma Comissão de Mantenedores de Polos e representantes da Instituição, vai de encontro a perspectiva de RIBEIRO (2007) que afirma que,

(...) A educação a distância, quando trabalhada numa perspectiva de economia de escala, pressiona por uma abordagem profissional de gestão, a qual pressupõe, além de infraestrutura tecnológica, um planejamento eficaz, dinâmico e adequado frente às demandas de atendimento dos clientes externos e internos de uma IES. (RIBEIRO, 2007, p.1)

Com o crescimento acelerado do número de Polos parceiros das três instituições de ensino superior que compõem o Grupo Educacional, a comunicação com essas unidades para ouvir suas dificuldades operacionais e sugestões para melhoria dos processos EaD ficou limitada.

Surge então em 2017, a proposição de se criar um grupo de estudo, por meio da constituição de uma Comissão de Mantenedores de Polos EAD, articulada pela Coordenação Geral de Polos e Coordenação dos Cursos de Graduação, com o intuito de, discutir questões relativas a busca de melhoria na relação Polo e Universidade com a finalidade de um atendimento de excelência ao aluno.

Por ato próprio, formalizada por Portaria da Pró-Reitoria de Educação a Distância se constitui a Comissão Permanente de Mantenedores de Polos de Educação a Distância, de caráter propositivo e deliberativo, que com base nos PDIs vigentes das 3 IES credenciadas para EaD e no Planejamento Anual da EaD do grupo educacional, que deve atuar de forma colaborativa para apresentação de propostas e ações para o aperfeiçoamento das atividades acadêmico-administrativas para o período de designição inicial dos membros indicados de um ano 
Como princípios norteadores do trabalho definiu-se na referida portaria que :

As ações iniciadas no âmbito dessa comissão serão de caráter analítico e reflexivo, de maneira a apresentar ações inovadoras e sustentáveis para a oferta dos cursos e programas na modalidade a distância e demais assuntos.

É imprescindível, ainda, que a Comissão tenha como foco:

- Alinhamento das avaliações de aprendizagem com o Exame Nacional de Desempenho dos Estudantes (ENADE) e com concursos públicos;

- Desenvolvimento dos alunos em relação aos estudos, para que estes possuam as competências necessárias para atuarem como um profissional do Século XXI

- Formação acadêmica de qualidade.

A Comissão é composta por representantes das áreas internas do grupo educacional, que atuam na gestão do EaD e mantenedores representantes dos polos parceiros, indicados pelos gestores internos, em função de suas competências como gestores de polos e grau de conhecimento sobre processos acadêmicos e administrativos da EaD do grupo educacional.

Cada mantenedor participante da comissão, representa um grupo de outros mantenedores parceiros e deve manter a comunicação e relacionamento com os mesmos para transmitir as tratativas ocorridas no âmbito da comissão e também para receber solicitações e sugestões de ações que possam contribuir para o propósito estabelecido para a criação da comissão.

A duração do mandato do primeiro grupo constituído foi de um ano e sua renovação está prevista para acontecer considerando candidaturas de novos mantenedores que atendam o perfil inicialmente definido pela IES e corroborado pela comissão que substituirão pelo menos $50 \%$ dos representantes atualmente constituídos.

Antes desta iniciativa, a comunicação com os polos era realizada online, por meios de web conferências semanais com orientações gerais aos polos sobre os processos e deliberações da Universidade. Na ocasião os polos não participavam efetivamente da melhoria dos processos. Foi entendido pela Gestão Acadêmica do Grupo Educacional que representantes dos polos parceiros poderiam contribuir para a melhoria de processos das Universidades credenciadas para a $\mathrm{EaD}$, trazendo a visão daqueles que trabalham diretamente no atendimento dos seus alunos EaD. Essa medida trouxe aos polos o entendimento dos diferentes processos da Universidade nos setores: Acadêmico, Comercial, Fidelização, TI, Tutoria EaD, Financeiro, entre outros. 


\section{O desenvolvimento dos Trabalhos da Comissão}

Em seu primeiro ano de funcionamento foram realizadas reuniões mensais presenciais e via webconferência, simultaneamente, com aqueles representantes que estavam em localidades mais distantes. As pautas eram decididas em conjunto de acordo com a demanda gerada nos polos e novas diretrizes da Universidade sobre determinados processos.

Inicialmente foi definida um conjunto de temas considerados como mais relevantes para discussão. São eles:

$1^{\circ}$ Atividades Presenciais - ENADE

$2^{\circ}$ Análise Curricular

$3^{\circ}$ Prazos e Respostas para os processos abertos pelos alunos na Central de Atendimento ao Aluno - CAA ON-LINE

$4^{\circ}$ Processo de Avaliação

$5^{\circ}$ Cursos Técnicos

6 Pós Graduação

7ํㅡstágio Obrigatórios e Remunerados

8ㅇ Colação de Grau (Reunião realizada: 07/12/17);

9 Tutoria Online

$10^{\circ}$ Setor do T.I.

Nas reuniões os polos eram informados sobre as metodologias sistêmicas que formam as diretrizes da Universidade, e esclarecimentos do funcionamento e fluxos dos processos, dando maior entendimento sobre todo o sistema de ensino EaD do Grupo Educacional. Este conhecimento mais detalhado sobre os processos passou a ser transferido ao aluno com orientações precisas e com o aumento da credibilidade de nosso aluno com o polo e com a Instituição.

Na discussão e análise dos temas elencados eram feitas proposições para análise das áreas internas envolvidas, baseadas nas inconformidades verificadas pelos dos gestores de polos participantes, durante o atendimento dos alunos e na operacionalização dos processos acadêmicos e administrativos. Nas propostas encaminhadas buscou-se prioritariamente atender as premissas de viabilidade técnica e de sustentabilidade organizacional.

Além do estudo e proposição de ações para o aprimoramento do atendimento e formação acadêmica dos alunos, o motivo maior do trabalho de todos, se desenvolveu 
entre os participantes um clima muito positivo de relacionamento que contribuiu significativamente para a aproximação do grupo educacional com os seus polos parceiros e desconstruindo visões equivocadas sobre a atuação profissional de uma parte para com a outra.

\section{Resultados Alcançados pelo Trabalho da Comissão}

Nesse primeiro ano de atuação, a Comissão Permanente de Mantenedores alcançou resultados importantes que já foram implementados e que trouxeram contribuições significativas para os objetivos propostos com a criação desse grupo de trabalho. Descrevemos a seguir, alguns deles:

\section{Análise Curricular}

A entrada de novos alunos para os cursos de: Pedagogia para licenciados, R2, Segunda Graduação e pedidos de Transferência dependem de análises curriculares prévias. Neste sentido os prazos praticados estavam prejudicando a captação de novos alunos. Foi realizado a revisão do processo pela área responsável e se obteve inicialmente a redução do prazo para realização das Análises aos Polos de 9 para 5 dias úteis facilitando o trabalho de captação do polo. Houve também a ampliação dos horários para atendimento telefônico.

\section{Pós Graduação}

Após apresentação das dificuldades encontradas em relação à Pós Graduação, foram realizados várias webconferências com os gestores dessa área, esclarecendo os processos da Pós-Graduação e auxiliando nas demandas recebida pelo Polo. $O$ histórico dos Cursos da Pós-Graduação ficará disponível para consulta pela área do aluno, possibilitando ao discente acompanhar e consultar as disciplinas que o aluno tem a cursar, conforme o curso matriculado.

\section{Estágio}

Foram antecipados os avisos de Estágio relatando e auxiliando os Polos sobre os processos implantados. Houve a participação dos polos na indicação e contratação de Supervisores de Estágio para o curso de Serviço Social. Com o forma de orientar corretamente o aluno foram postados manuais e apresentado o detalhamento dos processos, para que os polos pudessem prestar melhor atendimento e esclarecimento ao aluno sobre os procedimentos de estágio. 


\section{Avaliação}

Foram ampliados os dias e horários para aplicação das provas, viabilizando mais alternativas para comparecimento para os alunos e otimizando os horários ociosos dos polos. Ocorreu também a antecipação do horário de liberação para impressão dos arquivos de prova presencial, possibilitando ao polo uma conferência prévia mais cuidadosa.

\section{Canais de Atendimento - Acadêmico}

Mudanças no atendimento aos alunos com a capacitação e padronização dos responsáveis pelo atendimento, padronização dos processos e melhoria na qualidade das respostas com foco no aluno.

\section{Cursos Livres}

Por solicitação da comissão passou a constar no Portal EAD do Grupo Educacional, a carga horária dos cursos oferecidos.

\section{Colação de Grau}

Divulgação de Portarias nomeando o Mantenedor do Polo, como representante do Reitor para apresentação da Colação de Grau e padronização de vídeo apresentando o Cerimonial de Colação de Grau para orientar os Polos com Pró-Reitor da Educação a Distância conferindo o Grau aos formandos. Foi elaborado o Juramento Universal para todos os cursos facilitando o andamento da cerimônia de Colação de grau nos polos. Os alunos dos cursos de R2, inicialmente não participavam da colação de grau, e recebiam apenas certificado de conclusão. Em última reunião foi deliberado que alunos de R2 participarão da cerimônia de colação de grau com o recebimento de diploma.

\section{Departamento do T.I.}

Apresentação da Restruturação do Departamento de T.I, prevista para implantação a partir de 2018 com o objetivo de obter maior agilidade e assertividade no processamento de dados e informações sobre os processos acadêmicos e administrativos relacionados com os cursos e alunos EAD

\section{NUPE- Núcleo de Práticas Educativas/ Atividades Presenciais}


Organização e planejamento para a realização das atividades presenciais nos polos EAD, com definição de procedimentos que sistematiza o Calendário com as atividades aprovadas e a operacionalização das mesmas, inclusive com a emissão automática de certificados de participação para os alunos.

\section{Enade}

Houve melhoria significativa na informação passada aos alunos e aos polos e um suporte maior e incentivo ao aluno.

\section{Comercial EAD}

Houve a liberação da aplicação que permite ao Polo realizar diretamente o cadastro do desconto para o aluno. Desenvolvimento de novo processo de rematrícula em conjunto com negociação facilitada de dívidas para alunos inadimplentes. Redução dos valores a serem pagos para alunos com dependências a cursar.

\section{Considerações Finais}

Após um ano de atuação, pode-se perceber que a prática da gestão integrada e participativa das Instituições de Ensino Superior com os seus Polos EaD parceiros pode trazer contribuições positivas para o aprimoramento dos processos acadêmicos e administrativos que colaboram para o melhor atendimento e relacionamento com os alunos.

Constatou-se também a possibilidade do desenvolvimento da visão sistêmica para todos participantes da comissão, considerando inclusive a atuação do polo ead, o que amplia o conhecimento e a perspectiva de decisões mais assertivas dos gestores e que poderão possibilitar a redução de inconformidades operacionais, prejuízos financeiros e perda de credibilidade organizacional.

Mas certamente o maior beneficiário dessa ação institucional passa a ser o aluno que terá mais atenção de todas as áreas quando estiverem planejando o curso e o seu atendimento a fim de transformá-lo num profissional competente e diferenciado no seu mercado de trabalho e na sociedade da qual faz parte.

Referências:

BARROS, M. C. M. S. (et. all). Educação a distância: a relevância do uso da tecnologia 
a favor da educação. Disponível em https://eventos.set.edu.br/index.php/enfope/article/view/5453. Acesso em 15/05/2018.

BRASIL.MEC. Lei n. 9.394, de 20 de dezembro de 1996. Diário Oficial da União, Brasília, DF, 1996.

Referenciais de qualidade para educação superior a distância. Brasília, Agosto de 2007.

Decreto n. 9.057, de 25 de maio de 2017, DOU 26 de maio de 2017a.

Portaria n. 11, de 20 de junho de 2017, DOU 21 de junho de 2017b.

Decreto n. 9.235, de 15 de Dezembro de 2017, DOU 16 de dezembro de 2017c.

INEP/MEC. Instituto Nacional de Estudos e Pesquisas Educacionais Anísio Teixeira. Sistema Nacional de Avaliação da Educação Superior (Sinaes). Brasília, 2015, v. 5. Instituto Nacional de Estudos e Pesquisas Educacionais Anísio Teixeira. Censo da educação superior 2016. Brasília, DF, 2016.

MOORE, M. G.; KEARSLEY, G. Educação a distância: uma Visão Integrada. São Paulo : Cengage Learning, 2008.

RIBEIRO, L. O. M. (et. al). Gestão de EAD: a importância da visão sistêmica e da estruturação dos CEADs para a escolha de modelos. CINTED-UFRGS - Novas Tecnologias na Educação. V. 5 № 1, JULHO 2007. Disponível em http://www.seer.ufrgs.br/renote/article/viewFile/14316/8229. Acesso em 10/05/2018 